\title{
Comparative assessment of water surface level using different discharge prediction models
}

\begin{abstract}
Discharge is traditionally measured at gauge stations located at discrete positions along the river course. When the volume of water discharge is higher than the river bank, inundation to adjacent land occurs. Flood inundation mapping has largely relied on in situ discharge data. However, it cannot be accessed at ungauged sites. In recent literature, no comparative study on the impact of water level using different discharge models has been carried out. This paper evaluates the performance of three empirical formulas for discharge measurement to model flood inundation along Padang Terap River in Kedah, Malaysia, between October 31, 2010 and November 4, 2010. Water discharge was computed using three models, and the Manning$\mathrm{n}$ values were assigned to the types of land use. Further, the rainfall obtained from gauge stations was interpolated using the Kriging interpolation method. Relative error and RMSE methods were used to evaluate the measured and predicted water surface elevation. The impact of predicted water surface elevation (WSE) from different land use types and terrain information was assessed. Dingman and Sharmaôs model significantly presented good agreement between measured and predicted WSE with R $2=0.8034$, followed by Manning and Bjerklie equations with 0.8024 and 0.7997 , respectively. Moreover, Dingman and Sharmaôs model produced less RE and RMSE with $13.09 \%$ and 2.27 m compared with the others. Therefore, the estimated discharge can be used in ungauged sites for flood inundation modeling. Manning-n, elevation, and slope affected the WSE.
\end{abstract}

Keyword: Discharge; Water level; Flood; GIS; Remote sensing; Malaysia 